\title{
Does Aspirin help or damage the liver?
}

Dr. Carolina Diamandis ${ }^{1}$, Alexandros Balaskas ${ }^{2}$, Olga Ivanova ${ }^{2}$, Marius Lazar ${ }^{2}$, and Lucas Smith $^{2}$

${ }^{1}$ Affiliation not available

${ }^{2}$ LCG Research Dr, Carolina Diamandis

December 3, 2021

\begin{abstract}
Aspirin is one of the most widely used medicines in the world and has been on the market for over a century. Therefore, it is surprising that little solid research has been done regarding the effects of aspirin on the liver. If anything, you can find a few studies from the 1970s. At that time, aspirin was described as damaging to the liver by quite some authors. But since the turn of the millennium, studies have suddenly appeared that attribute a liver-protective effect to aspirin. We have investigated this contradiction and found a tipping point effect of high clinical relevance.
\end{abstract}

\section{Hosted file}

Aspirin Liver Report 2021 Lazar Group 8-2.pdf available at https://authorea.com/users/410930/ articles/547897-does-aspirin-help-or-damage-the-liver 